\title{
Risk factors for Shiga toxin-producing Escherichia coli infections in preadolescent schoolchildren in Buenos Aires, Argentina
}

\author{
Adriana B. Bentancor ${ }^{1}$, Luis A. Ameal ${ }^{1,2}$, Maria F. Calviño ${ }^{1,2}$, Maria C. Martinez ${ }^{2}$, Luciano \\ Miccio $^{2,3}$, Osvaldo J. Degregorio ${ }^{4}$ \\ ${ }^{1}$ Cátedra de Microbiología, Facultad de Ciencias Veterinarias, Universidad de Buenos Aires, Chorroarín 280, \\ CP1427, CABA, Argentina \\ ${ }^{2}$ Programa de Voluntariado Universitario, Ministerio de Educación de la Nación Argentina \\ ${ }^{3}$ Cátedra Química Orgánica de Biomoléculas, Facultad de Ciencias Veterinarias, Universidad de Buenos Aires, \\ Argentina \\ ${ }^{4}$ Cátedra de Salud Pública, Facultad de Ciencias Veterinarias, Universidad de Buenos Aires, Argentina
}

\begin{abstract}
Introduction: Shiga toxin-producing Escherichia coli (STEC) infections are the leading cause of hemolytic uremic syndrome (HUS). STEC is the most common cause of acute kidney disease, responsible for $20 \%$ of renal transplants in Argentina.

Methodology: In 2007, an epidemiological survey was conducted among 883 students from the fifth and sixth years of elementary education in the public schools of San Martin City, Buenos Aires, Argentina. Degree of exposure to the known risk factors previously detected in the region as primary causes of STEC infections was evaluated. Risk factors assessed included consumption of hamburgers, poor personal hygiene, and exposure to various types of drinking and recreational water. The study was designed to evaluate exposure to risk factors for STEC infections among different socioeconomic groups.

Results: Ninety-five percent of children surveyed reported consumption of hamburgers. Most of these hamburgers were precooked. Children of high and medium strata attended private swimming-pools, while children from the low stratum attended public pools. Only $30.2 \%$ of students washed their hands after going to the toilet and only $43.5 \%$ reported hand-washing before eating.

Conclusions: Students demonstrated high levels of exposure to identified risk factors for STEC infections. Reduction of these risks will require cultural changes aimed at decreasing morbidity caused by food-borne infections. Institutional framework must provide the necessary resources to implement these changes and emphasize the importance of good personal hygiene. Health education must be implemented to increase food safety awareness of the consumers.
\end{abstract}

Key words: Shiga toxin-producing Escherichia coli; risk factors; food-borne disease

J Infect Dev Ctries 2012; 6(5):378-386.

(Received 28 January 2011 - Accepted 09 May 2011)

Copyright (C) 2012 Bentancor et al. This is an open-access article distributed under the Creative Commons Attribution License, which permits unrestricted use, distribution, and reproduction in any medium, provided the original work is properly cited.

\section{Introduction}

Shiga toxing-producing Escherichia coli (STEC) is one of the most important groups of emerging foodborne pathogens of worldwide distribution and the principal cause of hemolytic uremic syndrome (HUS). This syndrome, characterized by acute renal failure, hemolytic anemia and thrombocytopenia, is usually secondary to acute infectious diarrhoea [1]. Most cases of HUS are identified in children younger than 16 years old with a high incidence in children up to five years of age [2-6]. In Argentina, HUS is endemic with over 450 sporadic cases recorded per year. HUS is directly responsible for $20 \%$ of pediatric renal transplants in Argentina, and represents a critical area for further research [7-8]. Almost all diarrhoea- associated HUS cases in children are due to STEC infections belonging to $\mathrm{O} 157: \mathrm{H} 7$ or non $\mathrm{O} 157: \mathrm{H} 7$ serotypes [9]. The normal habitat of STEC is the intestinal tract of ruminants and other animals; particularly sheep and cattle serve as reservoirs [10]. The prevalence of STEC in ruminants is reported to be $66.6 \%$ in sheep, $56.1 \%$ in goats, and $21.1 \%$ in cattle [11]. The main route of human exposure is fecal-oral, usually due to fecal contamination of foods. In humans, less than 100 bacteria per gram of food are necessary to establish STEC infection [12]. The World Health Organization (WHO) has classified illness from STEC as a food-borne disease (FD) [13].

Transmission of disease can also occur through direct contact of humans with carrier animals, or 
Figure 1. Distribution of schools surveyed in various socioeconomic levels of San Martin, Buenos Aires, Argentina

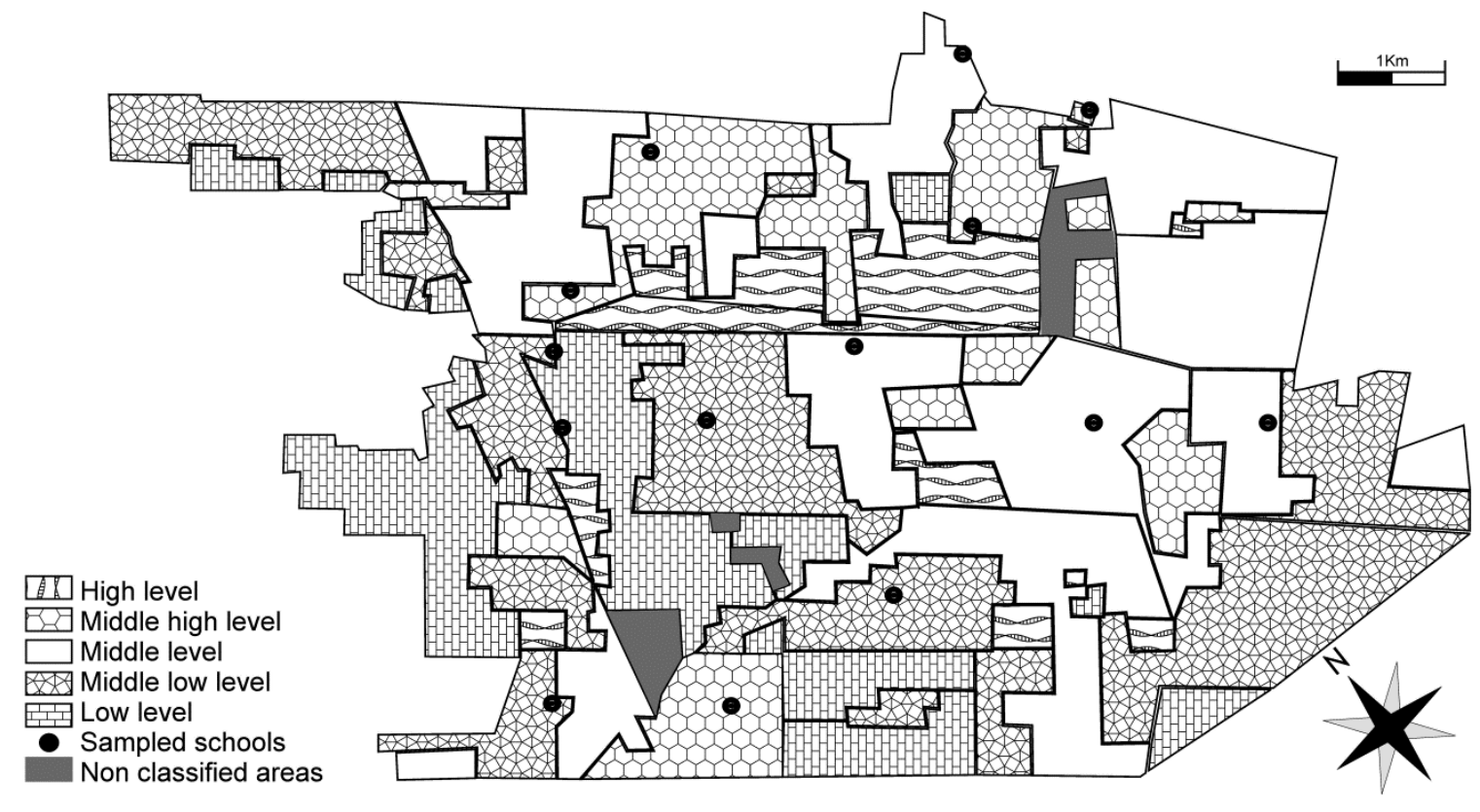

through person-to-person transmission. Food is identified as the source of infection in approximately half of all reported cases [14]. Previous studies have evaluated the importance of various risk factors for infection in humans. Contamination of ground meat can occur during processing or preparation and represents a potentially significant source of STEC. Bacteria are destroyed at $72^{\circ} \mathrm{C}$, but it is necessary to ensure that this temperature penetrates the whole of the meat prior to consumption [15]. Epidemiological studies have identified a number of useful measures to prevent possible human exposure to food-borne STEC infections. These include thorough cooking of meat (particularly ground meat), avoidance of crosscontamination during food preparation, access to safe drinking water, consumption of pasteurized milk and juices, as well as public education on the importance of good personal hygiene and cleanliness of eating utensils [16,17]. These measures complement actions aimed at lowering the prevalence of STEC in cattle [18], observing good hygiene practices during slaughter in meat processing plants, and careful preparation of meat for distribution to consumers [19].

The relationship between exposure to STEC and associated morbidity from diarrhoea among different socioeconomic groups has been extensively demonstrated [20]. Unsafe water, poor sanitation, and poor personal hygiene are three of the 10 identified risk factors for exposure to STEC. Worldwide, approximately 1.7 million deaths per year from infectious diarrhoea are attributable to these three factors [21]. Recent epidemiological results highlight the importance of socioeconomic risk factors in rates of disease associated with E. coli O157 [22]. Nevertheless, how socioeconomic level relates to these individual risk factors is unknown and warrants further evaluation [23].

The objective of the current study was to evaluate degree of exposure to STEC in the most vulnerable group: young schoolchildren. This goal was accomplished by assessing exposure to known risk factors for the development of HUS and their relation to the socioeconomic level of schoolchildren from urban areas in Buenos Aires.

\section{Methodology}

Study group

In total, 883 questionnaire surveys targeted at children in the 5th and 6th years of primary school (ages 10 to 12 years) were sent by professional surveytakers. The children attended 14 of the 56 state schools in an urban area of Buenos Aires, San Martin district, during 2007. This district is representative of the urban ring of Buenos Aires. Ethical approval for the study was obtained from the Department of Promotion and Prevention of Public Health Services of San Martin district.

The study was stratified by socioeconomic level because of the known association between the prevalence of childhood diarrhoea and economic inequalities. Documentary information was obtained from the National Institute of Statistics and Census 
(INDEC), which defines the socioeconomic levels of the district of San Martin as high, medium-high, medium, medium-low and low [24] (Figure 1).

The 56 tuition-free public schools of the district were geo-referenced and included in the distribution maps of socioeconomic level through a system of Cartesian coordinate axes.

For this study, the five socioeconomic levels (INDEC) were partially combined to create three groups: high (high and medium-high), medium (medium) and low (medium-low and low). Students representing $25 \%$ of each socioeconomic level were selected by simple random sampling from each school.

\section{Survey}

Grade, school attended, and area were recorded for each student. Exposure to known multiple factors was assessed. The following factors were included in the assessment:

1. Consumption of hamburgers
a. meat purchased from supermarkets
b. commercially butchered meat
c. home prepared hamburgers
d. meat purchased precooked for consumption

2. Type of water available for consumption

a. public drinking water from wells

b. commercially bottled water

c. other types of drinks frequently consumed

3. Exposure to recreational water
a. family swimming pools
b. public swimming pools
c. lakes, rivers or seas

4. Personal hygiene
a. hand-washing
b. time of day hands were washed

\section{Statistical analysis}

Statistical analysis data was processed by the program EpiInfo 2002 ver.3.2 (CDC-WHO). The statistical analysis of the variables under study, as classified by socioeconomic level, was by the Chi square independence test and the $\mathrm{Z}$ test to compare two proportions. We estimated odds ratios with $95 \%$ confidence intervals (CI) [25].

\section{Results}

Study group characteristics

Ranking the schools according to socioeconomic distribution revealed that of the 56 public schools identified in the district, $12(21 \%)$ belonged to the high level, $18(32 \%)$ to the middle level, and $26(46 \%)$ to the low level [24]. Based on the previously described sampling method, information was collected for all children present on the day of the survey-takers' visit in three schools from the high socioeconomic level (110 respondents), five schools in the middle level (394 respondents), and six schools in the low level (379 respondents) (Table 1). No significant differences were found among socioeconomic levels when comparing the distribution of schools sampled within the district $(\mathrm{p}=0.963)$, the respondent groups $(p=0.071)$, or the two grades surveyed $(p=0.065)$.

\section{Exposure to risk factors}

Hamburger consumption: Of students surveyed, $94.6 \%(835 / 883)$ said they consumed hamburgers. Confidence intervals for types of hamburger consumed and the absolute and relative frequency of consumption are presented in Table 2 .

Analysis of the data by socioeconomic status showed significant differences in the overall consumption of hamburgers, with the highest proportion in the high and middle levels $(p=0.001)$. There was no significant difference $(p=0.11)$ in the types of hamburgers consumed among the socioeconomic groups (Table 2).

Drinking water: Proportions of water consumption by socioeconomic strata were as follows: in students from the high-level socioeconomic group, 95 of $110(87.0 \%)$ students reported drinking water, 350 of $394(89.0 \%)$ in middle group, and 359 of $379(94.0 \%)$ in the low-level group (Table 3). The analysis of water consumption by socioeconomic status showed no significant differences $(p=0.08)$. Fifty-one (51) out of 804 (6.3\%) who consumed water reported that the source of the water was from a well. Three hundred fifty-four out of the 804 (44.0\%) students who consumed water also consumed other types of drinks: 276/354 (77.9\%) soda, 33/354 (9.3\%) fruit juices, $37 / 354(10.5 \%)$ both soda and fruit juices, and 8/354 (2.3\%) miscellaneous types of drinks (Table 4). Fifty-six students reported not consuming water, specifying other type of drink: 34/56 (60.7\%) soda, $1 / 56(1.8 \%)$ juice, $3 / 56(5.4 \%)$ both soda and juice, and $18 / 56(32.1 \%)$ several other drinks (the last three values were included as other in the table). Of all 883 students, $23(2.7 \%)$ did not indicate their drink consumption patterns.

Recreational water: Analysis of exposure to recreational water showed that $853 / 883(96.6 \%)$ of the children spent time swimming. A total of $636 / 853$ (74.6\%) respondents reported that they used family swimming pools, 296/853 (34.7\%) used public 
swimming pools, $255 / 853(29.9 \%)$ swam in the sea, $156 / 853(18.3 \%)$ swam in rivers, and $42 / 853(4.9 \%)$ swam in lakes (Table 5). Differences between children going to private/family swimming pools from different socioeconomic groups were not significant $(\mathrm{p}=0.010)$. However, $47 \%$ of children from the middle and highlevel socioeconomic groups who use family swimming pools (n: 354) also move to the sea during school holidays (n: 168) $(\mathrm{p}=0.000)$.

Personal hygiene: Of the children surveyed, $815 / 883$ (92.3\%) washed their hands while 68/883 $(7.7 \%)$ did not. Time of hand-washing is detailed in Table 6. In addition, 499/883 (56.5\%) of respondents reported that they never washed their hands before eating. Children from low socioeconomic levels washed their hands more frequently than those from other socio-economic groups did $(\mathrm{p}=0.000)$. Out of 379 students from the low level, $206(54.0 \%)$ reported washing their hands regularly as compared to 31 of $110(28.0 \%)$ and 147 of $394(37.0 \%)$ from the high and medium-level groups, respectively. The odds ratio for washing hands before eating was 36.02 (CI 4.94262.64).

\section{Discussion}

This study evaluated exposure of schoolchildren population to known risk factors for developing HUS [9]. The study group was comprised of children up to 15 years old represent one of the populations known to be at high risk $[6,15,17]$.

One risk factor strongly associated with HUS is meat consumption, particularly ground meat. A previous study using a case-control design showed an association between infection with STEC O157 and consumption of incompletely cooked hamburgers in the week prior to illness [26]. This study showed that $94 \%$ of children surveyed consumed hamburgers from a variety of sources. Differences among socioeconomic strata were in the frequency of consumption and not in the method of preparation.

In the last two generations, the consumption of precooked food has become widespread due to convenience, affordability, palatability and strong advertisement. This has resulted in substantial changes in handling methods for ground meat that place consumers at higher risk of exposure to undercooked meat. Changes in food handling such as inadequate cooking can contribute to the survival of pathogens in the meat with associated development of food-borne diseases. In Argentina, where meat consumption is estimated to be $63 \mathrm{~kg} /$ person/year [27], consumption of fast food increases the risk of exposure to pathogens, including STEC.

In the present study, nearly $80 \%$ of children consumed commercially prepared precooked hamburgers that were sold at stores regulated by the agency for Hazard Analysis and Critical Control Point (HACCP) and evaluated by health authority activities. Large numbers of children (60\%) from all socioeconomic groups also reported consumption of homemade hamburgers. Meat handling and preservation methods at home can also contribute to the risk of cross-contamination with an associated increase in the number of pathogenic organisms in the meat $[9,28]$. Preparation methods of homemade hamburgers would naturally vary among different homes. Therefore, the role of the government in educating the general public in proper food handling is crucial to reducing the risk of meat contamination in the target population. The Argentine Food Code legislation bans the sale of previously ground beef in retail stores [29]. However, the beneficial effects of this law depend on the efficiency of meat inspection by regulatory authorities [27].

The population studied showed minimal exposure to untreated drinking water. Only $6.3 \%$ consumed well water that could be of poor quality and represent potential risk. Consumption of other beverages consisted primarily of soft drinks that do not carry an associated risk for HUS. A smaller percentage of children reported consumption of juices. Consumption of commercially prepared non-pasteurized apple juice has been associated with cases of HUS in the United States [30]. In Argentina, commercial juices are pasteurized and should not represent a potential source of contamination.

In Argentina, some cases of HUS are associated with contaminated recreational water [13,31]. Children generally play for long periods of time in recreational waters and are more likely to intentionally or accidentally swallow water [32]. The current study group showed high exposure to family-owned swimming pools. Although initial water quality may be safe, inadequate maintenance of pools represents a potential risk factor. Thus implementation of adequate chlorination protocols is necessary to reduce disease associated with contaminated pond water. Educating individuals regarding proper pool maintenance and its role in disease prevention is critical. In high and medium strata, this probable risk situation is reduced to the half in holyday, when children break to move to the sea. Moreover, fewer children in low strata use the 
Table 1. Distribution of schools and students surveyed according to socioeconomic level

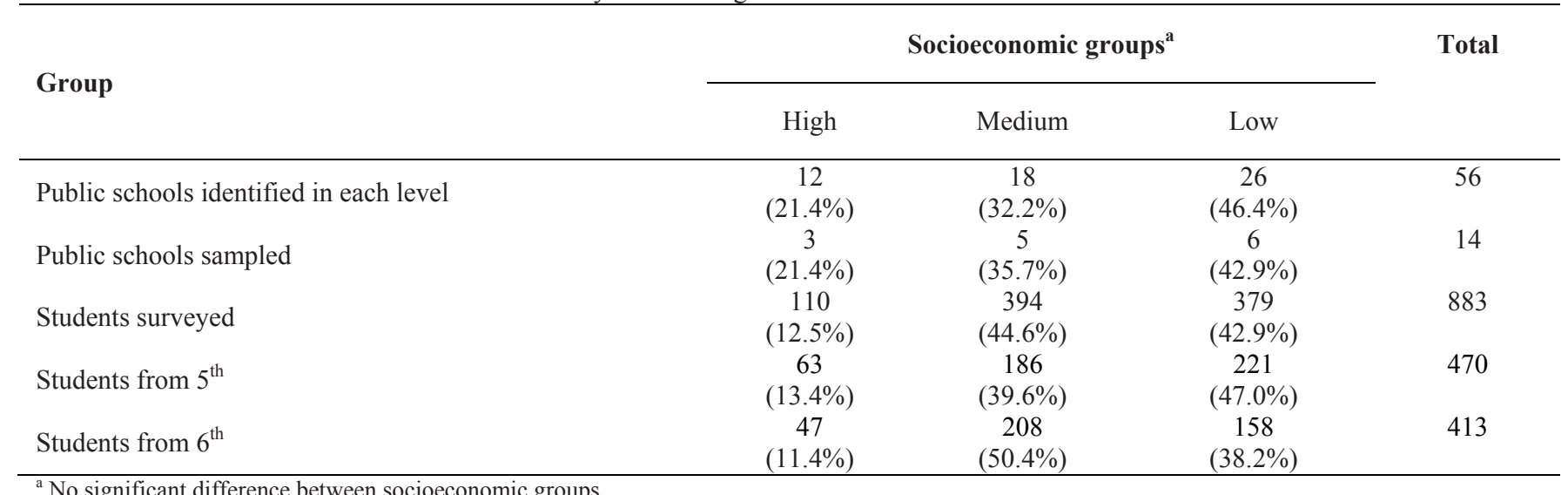

${ }^{a}$ No significant difference between socioeconomic groups

Table 2. Hamburger consumption in students aged 10-12 years from different socioeconomic levels

\begin{tabular}{|c|c|c|c|c|c|c|c|c|}
\hline \multirow{2}{*}{$\begin{array}{l}\text { Hamburgers } \\
\text { Consumption }\end{array}$} & \multirow[t]{2}{*}{$\mathbf{N}$} & \multirow{2}{*}{$\begin{array}{c}\text { Percent (\%) } \\
\text { Confidence } \\
\text { Interval (Ci) }\end{array}$} & \multirow{2}{*}{$\begin{array}{c}\text { Source of } \\
\text { Hamburguer }^{\mathrm{a}}\end{array}$} & \multicolumn{3}{|c|}{ Socioeconomic Groups } & \multirow[t]{2}{*}{ Total } & \multirow{2}{*}{$\begin{array}{l}\text { Percent (\%) } \\
\text { Confidence } \\
\text { Interval (Ci) }\end{array}$} \\
\hline & & & & $\begin{array}{l}\text { High } \\
(\mathrm{n}: 110)\end{array}$ & $\begin{array}{l}\text { Medium } \\
\text { (n:394) }\end{array}$ & $\begin{array}{c}\text { Low } \\
\text { (n:379) }\end{array}$ & & \\
\hline \multirow[t]{4}{*}{ Yes } & 835 & $\begin{array}{c}94.6 \\
(93.0-96.1)\end{array}$ & Homemade $^{b}$ & 66 & 242 & 221 & 529 & $\begin{array}{c}63.3 \\
(60.0-66.7)\end{array}$ \\
\hline & & & Supermarket $^{b}$ & 61 & 246 & 205 & 512 & $\begin{array}{c}61.3 \\
(57.9-64.7)\end{array}$ \\
\hline & & & Butcher $^{b}$ & 61 & 218 & 187 & 466 & $\begin{array}{c}55.8 \\
(52.4-59.2)\end{array}$ \\
\hline & & & $\begin{array}{c}\text { Cooked meals } \\
\text { stores }^{c}\end{array}$ & 80 & 333 & 290 & 703 & $\begin{array}{c}84.2 \\
(81.6-86.7)\end{array}$ \\
\hline No & 32 & $\begin{array}{c}3.7 \\
(2.6-5.2)\end{array}$ & - & - & - & - & - & - \\
\hline NR & 16 & $\begin{array}{c}1.7 \\
(0.9-2.9)\end{array}$ & - & - & - & - & - & - \\
\hline Total & 883 & 100 & - & - & - & - & - & - \\
\hline
\end{tabular}

NR: No response

${ }^{\text {a }}$ Frequencies considered on multiple responses

${ }^{\mathrm{b}}$ Considered as buying raw

${ }^{\mathrm{c}}$ Bought cooked for consumption

Table 3. Consumption of water and source in different socioeconomic strata

\begin{tabular}{|c|c|c|c|c|c|c|}
\hline \multirow{2}{*}{ Water Consumption } & \multirow{2}{*}{$\mathbf{N}$} & \multirow{2}{*}{$\begin{array}{c}\text { Percent (\%) } \\
\text { Confidence } \\
\text { Interval (CI) }\end{array}$} & \multirow{2}{*}{ Type of Water } & \multicolumn{3}{|c|}{ Socioeconomic Groups } \\
\hline & & & & High & Medium & Low \\
\hline \multirow[t]{2}{*}{ Yes $^{\mathrm{a}}$} & 804 & $\begin{array}{c}91.0 \\
(89.0-93.0)\end{array}$ & From well & 3 & 25 & 23 \\
\hline & & & Treated drinking water & 92 & 325 & 336 \\
\hline No & 56 & $\begin{array}{c}6.4 \\
(4.6-8.0)\end{array}$ & - & 11 & 28 & 17 \\
\hline NR & 23 & $\begin{array}{c}2.6 \\
(1.4-3.7)\end{array}$ & - & 4 & 16 & 3 \\
\hline Total & 883 & 100 & & 110 & 394 & 379 \\
\hline
\end{tabular}

\footnotetext{
${ }^{\mathrm{a}}$ No significant difference between socioeconomic groups.
} 
Table 4. Combinations of drink consumption in different socioeconomic strata

\begin{tabular}{|c|c|c|c|c|c|c|}
\hline Drinks Consumption & $\mathbf{N}$ & $\begin{array}{c}\text { Percent (\%) } \\
\text { Confidence } \\
\text { Interval (CI) }\end{array}$ & Combination & \multicolumn{3}{|c|}{ Socioeconomic Groups } \\
\hline Only water & 450 & $\begin{array}{c}55.9 \\
(52.5-59.5)\end{array}$ & - & 54 & 201 & 195 \\
\hline \multirow[t]{3}{*}{ Water \& other drinks } & & & water \& soda & 31 & 118 & 127 \\
\hline & 354 & 44.1 & water \& juice & 5 & 12 & 16 \\
\hline & & & water \& miscellaneous & 0 & 5 & 3 \\
\hline \multirow[t]{2}{*}{ Other drinks excluding water } & 56 & $\begin{array}{c}67.8 \\
(54.7-80.9)\end{array}$ & soda & 2 & 17 & 15 \\
\hline & & & other $^{\mathrm{a}}$ & 9 & 11 & 2 \\
\hline
\end{tabular}

${ }^{a}$ : Situations not covered by the previous options with low frequency $(\leq 3)$.

NR: No response

Table 5. Recreational water used according to socioeconomic level

\begin{tabular}{|c|c|c|c|c|}
\hline \multirow[b]{2}{*}{ Recreational water } & \multicolumn{3}{|c|}{ Socioeconomic groups } & \multirow{2}{*}{$\begin{array}{l}\text { Total } \\
\text { (n: } 883)\end{array}$} \\
\hline & $\begin{array}{c}\text { High } \\
(\mathrm{n}: 110)\end{array}$ & $\begin{array}{c}\text { Medium } \\
(\mathrm{n}: 394)\end{array}$ & $\begin{array}{c}\text { Low } \\
(\mathrm{n}: 379)\end{array}$ & \\
\hline $\begin{array}{l}\text { Number of respondents }{ }^{\mathrm{b}} \\
\text { (proportion) }\end{array}$ & $\begin{array}{c}\mathbf{1 0 4} \\
(94.5 \%)\end{array}$ & $\begin{array}{c}\mathbf{3 8 3} \\
(97.2 \%)\end{array}$ & $\begin{array}{c}366 \\
(96.5 \%)\end{array}$ & $\begin{array}{c}\mathbf{8 5 3} \\
(96.6 \%)\end{array}$ \\
\hline \multicolumn{5}{|l|}{ Type of recreational water ${ }^{\text {a }}$} \\
\hline Family swimming pools ${ }^{b}$ & 75 & 279 & 282 & 636 \\
\hline The sea & 29 & 139 & 87 & 255 \\
\hline Rivers & 20 & 65 & 71 & 156 \\
\hline Lakes & 9 & 14 & 19 & 42 \\
\hline
\end{tabular}

${ }^{\mathrm{a}}$ Corresponds to multiple responses from the total survey

${ }^{\mathrm{b}}$ No significant difference between socioeconomic groups.

Table 6. Hand-washing patterns and frequency in schoolchildren related to socioeconomic level

\begin{tabular}{|c|c|c|c|c|}
\hline \multirow[b]{2}{*}{ When hands were washed } & \multicolumn{3}{|c|}{ Socioeconomic groups } & \multirow{2}{*}{$\begin{array}{c}\text { Total }(\mathbf{\%})^{a} \\
\text { (n: } 883)\end{array}$} \\
\hline & $\begin{array}{c}\text { High } \\
(\mathrm{n}: 110)\end{array}$ & $\begin{array}{c}\text { Medium } \\
(\mathrm{n}: 394)\end{array}$ & $\begin{array}{c}\text { Low } \\
(\mathrm{n}: 379)\end{array}$ & \\
\hline Before eating & 31 & 147 & 206 & $384(43.5)$ \\
\hline After toileting & 19 & 121 & 127 & $267(30.2)$ \\
\hline Morning-Afternoon and Evening & 32 & 104 & 71 & $207(23.4)$ \\
\hline On returning home & 7 & 38 & 29 & $74(8.4)$ \\
\hline After touching something dirty & 2 & 31 & 22 & $55(6.2)$ \\
\hline When cooking & 4 & 19 & 11 & $34(3.8)$ \\
\hline In the morning & 0 & 5 & 6 & $11(1.2)$ \\
\hline Other ${ }^{b}$ & 10 & 26 & 17 & $53(6.0)$ \\
\hline
\end{tabular}

${ }^{\mathrm{a}}$ Corresponds to multiple responses from the total survey

${ }^{\mathrm{b}}$ Situations not covered by the previous options and low frequency $(\leq 3)$. 
recreational open water and therefore depend on the sanitary quality of the pools. Public swimming pools depended on current required regulatory inspections by qualified authorities to ensure water quality. The positive impact of such regulatory measures on health and safety has been previously documented $[33,34]$.

The importance of hygiene measures, particularly hand-washing, in the prevention of disease, including acute infantile diarrhoea, has been previously documented [34]. In Argentina, hand-washing has been identified as a protective factor in a multivariate analysis for STEC infection [9]. Therefore, in the current study, personal hygiene habits were assessed based on frequency and time of hand-washing. In the present study, schoolchildren generally practiced hand-washing but many of them did not wash their hands prior to eating food. Since hand-washing before eating is critical to the prevention of food-borne diseases, those who fail to wash their hands before eating are at risk of exposure.

Hand-washing should be considered an important preventive measure and strongly encouraged. However, most of the schools visited did not have the necessary elements of hygiene, such as soap in the bathrooms. Behavioral changes in these groups are unlikely without adequate infrastructure and appropriate institutional support.

All the identified risks are preventable through appropriate health and consumer education of children and their families. Consumer demand for a safe food supply must be addressed with an institutional framework maintained under governmental supervision. The government of Argentina has sporadically undertaken such prevention campaigns, but these measures have not demonstrated long-term impact on the incidence of disease. Short-term positive results, such as the decreased incidence of infant diarrhoea during the campaign to prevent cholera disease (Morales R, unpublished results, 2006), are occasionally reported. Unfortunately, none of these campaigns have resulted in lasting behavioral changes.

Given the endemic nature of HUS in Argentina, isolated and local campaigns are unlikely to reduce incidence of the disease. Implementation and sustainment of a national program for prevention and control will provide the greatest benefit to the general population. Health education programs should be directed at increasing awareness of food safety and adequate personal hygiene. The educational concepts that reduce the incidence of diarrhoea in developing countries are outlined in strategies promoted by the
Pan-American Health Organization (PAHO) and the World Health Organization (WHO) [35].

Encouraging individuals to take positive measures for improving food safety and hygiene measures is highly desirable and critical in the prevention of foodborne diseases. Reduction of risk also depends on cultural dietary changes that will help decrease the burden of infectious disease in developing countries [21].

More than 200 food-borne diseases with high morbidity and mortality rates in children are currently recognized. It is imperative to develop coordinated and integrated actions to decrease illness associated with these diseases. These illnesses also contribute to increased costs within the health-care system, have a strong social impact, and create distrust in the community regarding safety in the food chain. In particular, treatment costs associated with HUS significantly exceed the investment in prevention [8]. We contend that focusing on health risks is key to prevention of disease. Correctly implemented, highquality health programs that do not discriminate based on cultural and socioeconomic conditions will improve overall child health [36]. Such risk reductions and sustainable development may also help in reducing inequalities in the society. These changes are not only the responsibility of governments but the concern of all individuals within the population [21]. The current study demonstrates that Argentinian children are at high risk of exposure to known risk factors for the development of HUS. These findings confirm the need for improved educational programs targeted at improving personal hygiene, establishment of correct meat handling and cooking techniques, and maintenance of safe recreational water. Further studies are needed to identify appropriate educational methods targeted at different cultural and socioeconomic groups in the prevention food-borne disease.

\section{Acknowledgements}

The authors thank the staff of the Zoonosis Center of San Martín district, Raúl Eyherabide, Mónica Braida and Silvia Mónica Pelatti. They are also grateful to the Secretary of University Extension and Student Welfare, Faculty of Veterinary Sciences, UBA and the following students for their technical support and useful contributions: Fernanda Cichoki, Lucía Jimén

ez, Anabella Boggini, Eugenia Escudero, Samanta García, Cecilia Chocron, Mercedes Muschong and Magalí Aguirre.

This work was funded by the University Volunteer Program, Secretary of University Policy, Ministry of 
Education of Argentina SPU/PVU Res No. 668/2007, and UBACyT V401.

\section{References}

1. Griffin PM and Tauxe RV (1991) The epidemiology of infections caused by Escherichia coli O157:H7, other enterohemorrhagic E. coli, and the associated hemolytic uremic syndrome. Epidemiol Rev 13: 60-98.

2. Ministry of Public Health of Argentina (2009) Sala de situación, SUH. Available:

http://www.msal.gov.ar/htm/Site/sala_situacion/PANELES/Proble mas\%20emergentes/Nacional/SUH.gif. Accessed 02 August 2009.

3. Gerber A, Karch H, Allerberger F, Verweyen HM, Zimmerhackl LB (2002) Clinical course and the role of Shiga toxin-producing Escherichia coli infection in the hemolyticuremic syndrome in pediatric patients, 1997-2000, in Germany and Austria: a prospective study. J Infect Dis 186: 493-500.

4. Lynn RM, O'Brien SJ, Taylor CM, Adak GK, Chart H, Cheasty T, Coia JE, Gillespie IA, Locking ME, Reilly WJ, Smith HR, Waters A, Willshaw GA (2005) Childhood hemolytic uremic syndrome, United Kingdom and Ireland. Emerg Infect Dis 11: 590-596.

5. Gianantonio CA, Vitacco M, Mendilaharzu F, Gallo GE, Sojo ET (1973) The hemolytic uremic syndrome. Neprhon 11: 174-192.

6. Decludt $\mathrm{B}$, Bouvet $\mathrm{P}$, Mariani-Kurkdjian $\mathrm{P}$, Grimont $\mathrm{F}$, Grimont PA, Hubert B, Loirat C (2000) Haemolytic uraemic syndrome and Shiga toxin-producing Escherichia coli infection in children in France. The Société de Néphrologie Pédiatrique. Epidemiol Infect 124: 215-220.

7. Exeni RA (2006) Hemolytic uremic syndrome. Clinical manifestations. Treatment. Medicina (BAires) 66: 6-10.

8. Caletti MG, Petetta D, Jaitt M, Casaliba S, Gimenez A (2006) Hemolytic uremic syndrome (HUS): medical and social costs of treatment. Medicina (B Aires) 66: 22-26.

9. Rivas M, Sosa-Estani S, Rangel J, Caletti MG, Vallés P, Roldán CD, Balbi L, Marsano de Mollar MC, Amoedo D, Miliwebsky E, Chinen I, Hoekstra RM, Mead P, Griffin PM (2008) Risk factors for sporadic Shiga toxin-producing Escherichia coli infections in children, Argentina. Emerg Infect Dis 14: 763-771.

10. Tasara T, Bielaszewska M, Nitzsche S, Karch H, Zweifel C, Stephan R (2008) Activatable Shiga toxin 2d (Stx2d) in STEC strains isolated from cattle and sheep at slaughter. Vet Microbiol 131: 199-204.

11. Beutin L, Geier D, Steinrück H, Zimmermann S, Scheutz F (1993) Prevalence and some properties of verotoxin (Shigalike toxin)-producing Escherichia coli in seven different species of healthy domestic animals. J Clin Microbiol 31: 2483-2488.

12. Reilly A (1998) Prevention and control of enterohaemorrhagic Escherichia coli (EHEC) infections: memorandum from a WHO meeting. WHO Consultation on Prevention and Control of Enterohaemorrhagic Escherichia coli (EHEC) Infections. Bull World Health Organ 76: 245255.

13. Mead PS, Griffin PM (1998) Escherichia coli O157:H7. Lancet 352: 1207-1212.

14. Report of WHO Consultation on "Shiga-Like Toxin" Producing Escherichia coli, with Special Emphasis on Zoonotic Aspects Giessen, Germany, 10-12 December 1991.
Ref: WHO/CDS/VPH/92.103. Available: http://www.who.int/zoonoses/resources/foodborne/ en/ Accessed 27 April 2011.

15. Osaili TM, Griffis CL, Martin EM, Beard BL, Keener AE, Marcy JA (2007) Thermal inactivation of Escherichia coli O157:H7, Salmonella, and Listeria monocytogenes in breaded pork patties. J Food Sci 72: 56-61.

16. Lopez EL, Diaz M, Grinstein S, Devoto S, Mendilaharzu F, Murray BE, Ashkenazi S, Rubeglio E, Woloj M, Vasquez M (1989) Hemolytic uremic syndrome and diarrhea in Argentine children: the role of Shiga-like toxins. J Infect Dis 160: 469475 .

17. Bell BP, Griffin PM, Lozano P, Christie DL, Kobayashi JM, Tarr PI (1997) Predictors of hemolytic uremic syndrome in children during a large outbreak of Escherichia coli $\mathrm{O} 157: \mathrm{H} 7$ infections. Pediatrics 100: E12.

18. Oporto B, Esteban JI, Aduriz G, Juste RA, Hurtado A (2008) Escherichia coli $\mathrm{O} 157: \mathrm{H} 7$ and non-O157 Shiga toxinproducing $E$. coli in healthy cattle, sheep and swine herds in Northern Spain. Zoonoses Public Health 55: 73-81.

19. Petersen E, Vesco G, Villari S, Buffolano W (2010) What Do We Know About Risk Factors for Infection in Humans with Toxoplasma gondii and How Can We Prevent Infections? Zoonoses Public Health 57: 8-17.

20. Huttly SRA, Morris SS, Pisani V (1997) Prevention of diarrhoea in young children in developing countries. Bull World Health Organ 75: 163-174.

21. WHO Report (2002) The world health report 2002 - Reducing Risks, Promoting Healthy Life. Available: http://www.who.int/whr/2002/en/whr02 en.pdf. Accessed 04 April 2009.

22. Chang M, Groseclose SL, Zaidi AA, Braden CR (2009) An ecological analysis of sociodemographic factors associated with the incidence of salmonellosis, shigellosis, and E. coli O157:H7 infections in US counties. Epidemiol Infect 137: $810-820$

23. Pearl DL, Louie M, Chui L, Doré K, Grimsrud KM, Martin SW, Michel P, Svenson LW, McEwen SA (2009) A multilevel approach for investigating socio-economic and agricultural risk factors associated with rates of reported cases of Escherichia coli O157 in humans in Alberta, Canada. Zoonoses Public Health 56: 455-464.

24. INDEC (National Institute of Statistics and Censuses) Report (2006) Buenos Aires. Available: http://www.indec.mecon.ar/webcenso/index.asp. Accessed 10 August 2006.

25. Fleiss J (1981) Statistical Methods for Rates and Proportions, 2nd edition. New York: Wiley J and Sons Press 321 p.

26. Voetsch AC, Kennedy MH, Keene WE, Smith KE, RabatskyEhr T, Zansky S, Thomas SM, Mohle-Boetani J, Sparling PH, McGavern MB, Mead PS (2007) Risk factors for sporadic Shiga toxin-producing Escherichia coli O157 infections in FoodNet sites, 1999-2000. Epidemiol Infect 135: 993-1000.

27. Secretary of Agriculture, Livestock, Fisheries and Food of Argentina (2006) Report of Bovine Meat Market. Bovine meats consume. Bovine Meat Report. Buenos Aires; Available: $\quad$ http://www.sagpya.mecon.gov.ar/new/00/programas/dma/ganaderia/informes/info_carnes_ 2006.pdf. Accessed 10 May 2008.

28. Kassenborg HD, Hedberg CW, Hoekstra M, Evans MC, Chin AE, Marcus R, Vugia DJ, Smith K, Ahuja SD, Slutsker L, Griffin PM (2004) Emerging Infections Program FoodNet Working Group. Farm visits and undercooked hamburgers as 
major risk factors for sporadic Escherichia coli O157:H7 infection: data from a case-control study in 5 FoodNet sites. Clin Infect Dis 38: 271-278.

29. Argentine Food Code Law 18.284 (2007) Chapter VI. Article 255 - (SPRyRS y SAGPyA N 79 and 500/04). Available: http://www.anmat.gov.ar/codigoa/Capitulo_VI_Carneos_actu aliz_2007-08.pdf. Accessed 12 May 2009.

30. Centers for Disease Control and Prevention (CDC) (1996) Outbreak of Escherichia coli O157:H7 infections associated with drinking unpasteurized commercial apple juice- British Columbia, California, Colorado, and Washington. Morb Mortal Wkly Rep 45: 975.

31. Craun GF, Calderon RL, Craun MF (2005) Outbreaks associated with recreational water in the United States. Int J Environ Health Res 15: 243-262.

32. Guidelines for safe recreational water environments. Vol 1.Coastal and fresh waters. Available: http://www.who.int/water_sanitation_health/bathing/srwg1.pd f. Accessed 12 Dec 2011.

33. Castor ML and Beach MJ (2004) Reducing illness transmission from disinfected recreational water venues: swimming, diarrhea and the emergence of a new public health concern. Pediatr Infect Dis J 23: 866-870.
34. Heijne JCM, Teunis P, Morroy G, Wijkmans C, Oostveen S, Duizer E, Kretzschmar M, Wallinga J (2009) Enhanced hygiene measures and Norovirus transmission during an outbreak. Emerg Infect Dis 15: 24-30.

35. Cáceres DC, Estrada E, DeAntonio R, Peláez D (2005) Acute diarrheal disease: a public health challenge in Colombia. Pan Am J Public Health 17: 6-14.

36. Etchegoyen G and Paganini JM (2007) La relación entre los factores socioeconómicos y los programas sanitarios de salud maternoinfantil en 13 provincias argentinas. Rev Panam Salud Pública 21: 223-230.

\section{Corresponding author}

Adriana Beatriz Bentancor

Facultad de Ciencias Veterinarias

Universidad de Buenos Aires

Chorroarín 280, Ciudad Autónoma de Buenos Aires, Argentina Telephone: +54-11-4524-8421

Email: aben@fvet.uba.ar

Conflict of interests: No conflict of interests is declared. 